\title{
UN TEXTO CHIÍ EN CASTELLANO, DEL S. XVII, EN EL UNIVERSO CULTURAL ISLÁMICO DE LOS MORISCOS EXPULSADOS
}

\author{
José Francisco Cutillas Ferrer
}

La presente ponencia pretende mostrar algunas de las conclusiones del estudio de la primera parte del Ms. 565 de la Universidad de Bolonia, "Corónica y relaçión de la esclareçida deçendençia xarifa"1. Los trabajos precedentes se han centrado sobre el conjunto del Ms. D. $565^{2}$, y más en concreto sobre la parte central escrita por Ahmad al-Hayarî (Bejarano) ${ }^{3}$. El primer estudio que reparó en los elementos que son motivo de esta ponencia fue el trabajo del Dr. Juan Penella ${ }^{4}$, en el Coloquio Internacional de Literatura Aljamiada y Morisca (Oviedo, 1972). Esta aproximación fue la que me permitió interesarme por la primera parte del Ms. D. 565.

Todavía inédito, el Dr. Míkel de Epalza me animó a editarlo, sin suponer todavía las sorpresas que nos iba a deparar. Es posible que no existieran

1. Šarifa, "noble de nacimiento elevado". Se dice especialmente de los descendientes del

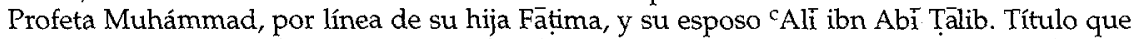
se aplicaba en particular a los encargados de los Lugares Santos de La Meca (los jerifes, soberanos más o menos autónomos, antes de la ascensión de los Saudíes en Arabia).

2. El Ms. 565 de la Biblioteca de la Universidad de Bolonia comprende tres partes bien diferenciadas con diferentes tipos de escritura según cada una de las partes y 313 folios. El primer tratado es "La Corónica de la esclareçida desçendençia xarifa". El segundo tratado es obra de Ahmed Bejarano sobre diferentes temas autobiográficos, piadosos, etc. $Y$ el tercer tratado corresponde a un devocionario práctico de la escuela Hánafi.

3. Ver Gerard WIEGERS, «A life between Europe and the Maghrib», en Orientations, ed. Geert Jan van Gelder and Ed de Moor, 1993, pp. 87-115; Juan PENELLA ROMA, "Introduction au manuscrit D 565 de la Bibliothèque Universitaire de Bologne», en Recueil d'études sur les moriscos andalous en Tunisie, Madrid-Tunis, ed. M. de Epalza y R. Petit, Dirección General de Relaciones Culturales, 1973, pp. 258-263; Juan Penella Roma, Los Moriscos españoles emigrados al norte de Africa después de la expulsión, Barcelona, Universidad de Barcelona, 1970, Tesis Doctoral.

4. Juan PENELLA, «El sentimiento religioso de los moriscos españoles emigrados: notas para una literatura morisca en Túnez», en Actas del Coloquio Internacional de Literatura Aljamiado y Morisca, Madrid, ed. Gredos (Cleam n 3), 1978, pp. 447-474. 
chiíes entre los moriscos, ya que los datos que tenemos sobre la situación anterior en la sociedad de Al-Andalus así nos hacen afirmarlo ${ }^{5}$. Sin embargo, y distanciándonos de esta situación en la península, después de una lectura de la "Corónica", es evidente que el texto que tenemos ante nosotros pertenece a la chía. Las características singulares de la primera parte de la "Corónica" escrita en castellano en Túnez en el año 1049/16396, permiten afirmar que en líneas generales la vida de los doce imames de la chía son citadas en el texto. Hasta aquí ya resulta novedoso. Sin embargo, todavía presenta otra novedad que posiblemente hubiera pasado desapercibida si no hubiera sido por el interés hacia el mundo y literatura en lengua persa que sembró la enseñanza de la Dra. Dña. María Jesús Rubiera Mata. La parte central y más extensa de la "Corónica", donde se narra la batalla de Karbalá (Iraq) y la muerte de Husáin, nieto del Profeta Muhámmad, corresponde a un tipo de literatura piadosa que se remonta al menos al año 352/963, cuando el Sultán Mucizz ad-Dawla ${ }^{7}$ dirigió las primeras ceremonias públicas de condolencia y lamento por la muerte de Husáin en Bagdad. En el período transcurrido desde estas primeras manifestaciones, hasta el reinado del Sultán Husain Mírzā Bāiqarā $\overline{-}^{8}$, en Herāt (Afganistán), fueron pasando del ámbito privado al público. Y más tarde, con la llegada de la dramatización de la tragedia de Karbalá, alcanzó su significado moderno y vino a desembocar en una forma novedosa de teatro.

El primer texto que, podemos decir, mantiene un vínculo con el tema de la muerte de Husáin de nuestra "Corónica", es el Rawdat aš-Suhadă' (El jardín de los mártires), escrito por Mulla Husain Wăciz Kăsifi ${ }^{9}$, que fue el primer maqtal ${ }^{10}$ en persa. En Bagdad Meḥmed ibn Sulaymān Fựūīî̉ escribió el

5. Ver Mahmud 'Alī MAKKİ, «At-tašayyu' fi-l-Andalus», en Revista del Instituto Egipcio de Estudios Islámicos en Madrid, Madrid, vol II, 1954, pp. 93-149; A. GHEDIRA, "Un traité inédit d'Ibn al-Abbār à tendeance Chiite», en Al-Andalus, Madrid, 1957, vol. XXII, fasc. 1, pp. 3054; IBN AL-ABBĀR, Durar al-simt fi Jabar as-sibt, Beirut, ed. Dar al-Garb al-Islami, 1987; María Isabel FIERRO BELLO, La Heterodoxia en Al-Andalus durante el período omeya, Madrid, Instituto Hispano Árabe de Cultura, 1987.

6. “...traduçido de/ arábigo en castellano en Túnez, año de 1049" (f. 1/r).

7. Mucizz ad-Dawla, Abu 1-Husain Ahụmad. Sultán Būyida. 303/915-356/967. E.I. (1913-1936), Leiden, ed. Brill, 1993, vol, VI, pp. 705-706.

8. Rey del Jurasán, nacido en Herät en 842/1438, reinando desde el año 873/1469-911/1506. Su corte fue la más brillante de Asia. Se rodeó de gran número de artistas y escritores. Fue el último de los reyes Timūridas. Cfr. E.I. (1913-1936), op. cit., vol. III, p. 343.

9. Prolífico escritor de Herāt durante el reinado del Sultán Husain Mírzā Bāiquarā. Murió en el año 910/1505. Entre sus trabajos destaca Ajlāq-i-Muhsini, un tratado de ética dedicado a Abu'l-Muhsin un hijo del Sultán, y también Rawḍat aššsuhadā'. Cfr. E.I. (1913-1936), op. cit., vol. IV, pp. $789-790$.

10. Nombre de lugar, "lugar de masacre"; ha desembocado en un tipo de género literario específico donde se narra la muerte de de Husáin y la Batalla de Karbalá.

11. Uno de los autores más célebres de la literatura clásica turca. Nació en Iraq (885/1480963/1556) en la época de dominación de la dinastía Aq-Qoyunlu, probablemente en 
primer maqtal en turco, llamado Hadĩ at as-Su'ada' (El jardín de los mártires) ${ }^{12}$. Ambos, siguiendo a Abu 1-Qāsim Mahmūd ibn 'Umar az-Zamajšríni ${ }^{13}$.

Señalaremos a continuación los elementos que permiten atribuir la filiación del texto a fuentes chiíes.

En el texto se evidencia una forma de tratar ciertos temas que parecería estar indicando un posible estado de taqiyy $a^{14}$ en el autor. La estructura de la "Corónica" plantea la duda de si el escritor intenta mantenerse fuera de posiciones que pudieran delatar la heterodoxia del texto para la mayoría de la sociedad sunní, donde vivían los moriscos hispanohablantes destinatarios del manuscrito. Así, para salvar este escollo, empieza la obra con el relato de la vida de los personajes más significativos del Islam en general, el Profeta Muhámmad, sus mujeres e hijos, los cuatro primeros califas $r \bar{a} \bar{s}^{v} i \bar{u} n^{15}$, introduciendo a continuación la vida del Imam Hasan donde comienzan a mezclarse elementos específicos de la escuela chií.

Otro elemento que permite evidenciar la filiación del texto a fuentes chiíes es el relato de acontecimientos hagiográficos de la vida de los doce imames de la chía. Ya al comienzo del manuscrito se lee después de la básmala ${ }^{16}$ :

"Corónica y relaçión de la esclareçida deçendençia xarifa. Los que binieron de Alí ebnu Abi Tálib y la muerte de el Huçáin, radi alahu anhu ${ }^{17}$. Y los que fueron prosiguiendo del..." ( $\left.f^{\circ} 1 r\right)$.

Se ve cómo el autor tiene efectivamente, la finalidad de exponernos breves relatos hagiográficos de los doce imames. Sin embargo hay un detalle en el siguiente folio relacionado con el tema de la taqiyya, que crea cierta perplejidad. Después de mostrarnos cuál es su intención, es decir, hablarnos de la

Karbalá. Entre sus obras más importantes destaca Leyla wü Mểnīn y ésta que es motivo de nuestro interés Hadikat as-Su'ada'. Fue enterrado en Karbalá, es muy probable que fuera chií. Cfr. E.I., op. cit., 1965, vol. II, pp. 958-961.

12. Cfr. Mayel BaKtash, «Ta'ziyeh and its Philosophy», en Peter J. CHelkowski, Ta'ziyeh, Ritual and Drama in Iran, Nueva York, ed. New York University Press, 1979, pp. 101-102.

13. Abu 1-Qäsim Mahmūd ibn 'Umar az-Zamajšrīi. Nació en Jwārizm (467/1074-538/1143). Teólogo y filósofo, siguió a la escuela filosófica de la $M$ c $^{c}$ tazila. Siendo ampliamente leído a pesar de su tendencia muctazilí. Ibn Jaldūn lo sitúa por encima de todos los comentadores del Corán. Recibió fuertes críticas de la escuela mälikï. Cfr. E.I. (1913-1936), op. cit., vol. VIII, pp. 1205-1207.

14. "Taqiyya, precaución, o kitmān, discreción, secreto, son vocablos técnicos con que se designa el acto con que uno, según su discreción, se exime del cumplimiento de deberes religiosos en caso de fuerza mayor o de temor de un daño considerable". Cfr. el artículo "Taqiyya o Kitmän», en F.M. PAREJA, Islamología, Madrid, ed. Razón y Fe, vol. II , pp. 725-726.

15. Referente a los califas perfectos o bien guiados: Abü Bakr as-Ṣiddīq, 'Umar ibn al-Jattāab, 'Uțmän ibn 'Affän y 'Alī ibn Abĩ Ṭàlib.

16. Fórmula de invocación: bismi l-lāhi r-rahłnāni r-rahim. "En el nombre de Alá, el Clemente, el Misericordioso".

17. Radìya l-Tăhu canhu. "Dios esté complacido de él". 
"esclareçida deçendençia xarifa" ( $\left.f^{\circ} 1 \mathrm{v}\right)$, comienza con una nueva básmala, y dice:

"No se podrá tomar Prinçipio a una obra como ésta y a lo que la ymajinaçión tiene propuesto sin encomendarla a el que es caussa de todas las causas y pedir a su dibina probidençia críe en mí graçia para que comiençe la presente obra que es tratar la bida y milagros de su querido el Múztafa Muhámad çalm, y de sus compañeros, de quien dixo:'Nadie diga mal de mis compañeros que son como las estrellas y el que los amare me ama a mí y el que los aboreçe, me aboreçe a mí...." (fo $1 \mathrm{v})$.

Este párrafo lleva a preguntarse si el autor o copista después de tener confeccionada la obra, la completó con esta parte introductoria ${ }^{18}$ de la vida del Profeta Muhámmad, su familia y sus compañeros, para hacerla más asimilable de cara a los moriscos y a las autoridades religiosas. Lo cierto es que plantea una ruptura, un querer mantener el sentido sunní, en una obra que fue planteada con el contenido chií que nos anticipa el primer párrafo del manuscrito, es decir, una relación hagiográfica de los doce imames de la chía, y el relato de la muerte de Husáin, que se estudiará más adelante. Todo esto confirma la idea de taqiyya o disimulo, que se desprende del texto.

Un personaje que resulta controvertido en el texto es Muáwiya ${ }^{19}$-el primer califa omeya- que para las fuentes chiíes presenta un perfil negativo, pues no en vano fue el que luchó contra Alí y accedió al poder desplazando a Hasan del liderazgo de la comunidad de creyentes. En el texto mantiene ciertas connotaciones positivas, que intentan adecuarse a lo que los moriscos tenían en su bagaje sunní. De hecho hay ciertas características en el texto que así lo denotan. Podemos ver lo siguiente en el manuscrito:

"Pues traspasado el halifado de Aly ebnu Abi Tálib, entró en su lugar el Haçan, su hijo cuya birtud fue tanta que abiendo sido halifa siete meses, traspasó la pesada carga en ombros de Maugya ben Çufian, el qual cargo perdió el nombre de halifa y se bolbió en nombre de Rey, como lo dixo el Mensajero de Allá çalm. El qual Maugya fue ombre justo y santo, temeroso a el Señor, en cuyo tiempo tubieron muchas bitorias de los infieles, de cuya bondad y santidad salió el hijo más malo [f $\mathrm{f}^{\circ} 26 \mathrm{r}$ ] que naçio de mujeres, como se berá adelante en la muerte de el Huçáin, radialahu anhu..." (fo 26v).

Como ya se puede entrever en el manuscrito, Yazid el hijo de Muáwiya ${ }^{20}$ encarna todos los males y depravaciones morales. Justo cuando

18. El primer capítulo (f. $1 \mathrm{v}$ al f. $13 \mathrm{r}$ ), trata de la vida del Profeta y su familia. A continuación viene un segundo capítulo (f. $13 \mathrm{v}$ al f. $26 \mathrm{v}$ ) que trata de los cuatro califas raxidun, y de Hasan y Husáin. El tercer capítulo (f. 26v al f. 65r) trata acerca de los descendientes de Alí ibn Abu Tálib, y la muerte de Husáin.

19. Ver el artículo «Mucāwiya, guerras, política interior», en F.M. PAREJA, op. cit., vol. I, pp. 9195.

20. Ver el artículo «Yazíd I. Husayn. Karbata’», en F.M. PAREJA, op. cit., vol. I, pp. 96-97. 
comienza el capítulo tercero en el manuscrito, donde se narra la muerte de Husáin en la Batalla de Karbalá, se relata la agonía de Muáwiya:

"...se halló a su cabeçera el Yaçit, su hijo, maldito sea de Allá. Y dixole a su padre:' A el fin padre mío, que mueres'. A lo qual respondió el bienabenturado padre:'Sí, hijo, porque toda cosa criada a de morir. $Y$ no quedará sino el que es eterno en su reismo ${ }^{21}$, el que es perfeto ser de bida, el que no le alcança ni toca $\left[f^{\circ} 26 \mathrm{v}\right]$ el morir, ni pasa el tiempo'..." (fo $27 \mathrm{r}$ ).

Es interesante resaltar que cuando Muáwiya transmite el gobierno a su hijo, lo hace bajo ciertas condiciones en favor de Hasan, que sin embargo Yazid nunca cumplirá:

"...Diçe la istoria que muerto el padre fue el hijo puesto en su asiento y lugar, a quien toda la jente acudió dándole el parabién de el cargo. Y él enpeçó a repartir el tesoro que estaba en el Beyte el $\mathrm{Mel}^{22}$ por sus alcaydes y soldados, y a quien él más se afiçionó si no fue a el Huçáin, hijo de Aly ebnu Abi Tálib, radi alahu anhu, que ni le dio cuenta de nada ni de quanto el padre le encomendó. Antes fue en todo a la contra...." ( $\left.\mathrm{f}^{\mathrm{o}} 28 \mathrm{r}\right)$.

La forma de tratar el traspaso del gobierno así como la introducción que hace sobre el Profeta Muhámmad, su familia y los cuatro primeros califas, supuestamente indicaría que está dirigiéndose a un auditorio mayoritariamente sunní, cuestión ésta que no presenta ningúna duda. Sin embargo, también aquí habría que resaltar la posible utilización que está haciendo de la taqiyya o disimulo, habitual entre los chiíes para ocultar su madhab ${ }^{23}$ o escuela doctrinal.

Otro dato a destacar en esta primera parte de la "Corónica" que parece cuanto menos curioso es el relato de un hadiz de los hechos de la vida de Omar en el que se narra el encuentro de Alí con Omar:

“...Diçen que lo topó un día Aly ebnu Abi Tálib, radi alahu anhu, fuera de la Midina corriendo sobre una camella y le dixo: 'Ya Omar, mucho trabajo as dado a los halifas después de tí. Respondió: 'Ya Aly, si se ba algo de aquello que estoy obligado a haçer por estar oçioso, se me pedirá por quenta.'..." (fo $16 \mathrm{r})^{24}$.

Confirmando la hipótesis de este trabajo el texto enumera elogiosamente los doce imames de la chía en el fo $21 \mathrm{r}$ :

“...De aquí adelante diremos las bienabenturadas ramas que de el hijo de Aly ebnu Abi Talib proçedieron, que fueron: El Haçan y El Huçáin, ya Aly Çeyd El Abdin, y Muhámad El Báquir, y Cháfar El Çidiq, y Muça El Cadím y Aly El

21. Se está refiriendo a Dios.

22. Casa del Tesoro.

23. Ver el artículo «Escuelas jurídicas», en F.M. PAREJA, op. cit., vol. II, pp. 520-524.

24. Nótese que el sentido de este hadiz es acusatorio para Omar. Es un indicio más de las fuentes chiíes en las que se está basando el autor de la "Corónica". 
Radi, y Muhámad El Canih, y Aly El Azcari, y El Haçan El Háliz, y Muhámad el Mehdi, y el conocido y aguardado. Y es el último de los aymat ${ }^{25}$. Y éstos son de la estirpe y casa de el Múztafa Muhámad çalm, de los lomos de Aly ebnu Abí Tálib y de Fátima" ( $\mathrm{f}^{\circ} 21 \mathrm{r}$ ).

En relación con este párrafo hay un detalle que no debe pasar desapercibido y es cuando habla del duodécimo Imam, dice de él que "...es el último de los aymat", es decir el último de los doce imames de la chía. Esto es además, especialmente significativo puesto que afirma la doctrina específicamente chií del imam oculto ${ }^{26}$.

El tercer elemento que permite evidenciar la adscripción del texto a la chía, es la parte más amplia y que supone un hecho novedoso en los textos moriscos. Me estoy refiriendo al relato de la muerte de Husáin en la Batalla de Karbalá. Corresponde al capítulo tercero del libro y abarca del fo $26 \mathrm{v}$ a $65 \mathrm{r}$. El relato es una variante de la taziyeh ${ }^{27}$ de origen persa, cuyo significado es "condolencia", "consuelo", "pésame". Taziyeh se llama también a las representaciones dramáticas que conmemoran la muerte de Husáin en la Batalla de Karbalá. Por su forma literaria, el capítulo del manuscrito dedicado a la muerte de Husáin se estructura como las taziyeh persas, mantiene los mismos temas argumentales y acontecimientos.

Sin embargo, a pesar de todas estas coincidencias, el manuscrito es anterior a los dramas de taziyeh en su forma moderna, es decir, como representaciones teatrales en recintos cerrados tal como se hace en las grandes ciudades de Irán y en otros países donde hay chiíes hoy en día ${ }^{28}$. Su antecedente se encuentra en las "Ruzeh- $\lceil a n y " 29$, donde el narrador, subido en un púlpito, va recitando de una forma libre e improvisada el Rawdat $a{ }^{\vee}$-Suhad $\bar{a}$ ', escrito por

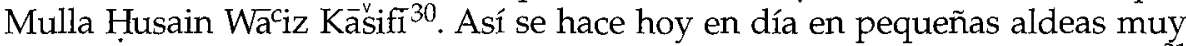
apartadas, donde no se dispone de un local para realizar taziyeh, y en los Dua ${ }^{31}$

25. Plural de Imām.

26. La doctrina del ocultamiento afirma la ausencia corporal del imam del tiempo, si bien sigue siendo el jefe de la comunidad islámica. Este punto es uno de los pilares de la escuela chía. Cfr. F.M. PAREJA, op. cit., vol. II, pp. 723-724. Sobre este tema ver capítulo "Nādar fí häal al-gaiba" y "Fì I-gaỉba", en AL-KuLAINI, Al-Käfi fi cIlm ad-Dìn, Teherán, ed. Dār al-kitäb al'islämiya, 1623 S., vol. I, pp. 333-343; M. Hussain JASSIM, The occultation of the Twelfth Imam, Londres, ed. Muhammadi Trust, 1982; Henry CORBIN (1972), En Islam iranien, ed. Gallimard, 1991; Moojan Momen, An Introduction to Shici Islam, New Haven, ed. Yale University Press, 1985, pp. 161-170.

27. Ver ta`ziya, en E.I. (1913-1936), op. cit., vol. VIII, pp. 711-712; F.M. PAREJA, op. cit, vol. II, p. 728.

28. Ver p. ej., el interesante trabajo sobre la comunidad chií en Hyderabad: David PiNAULT, The Shites, Londres, ed. I.B. Tauris \& Co. Ltd., 1992.

29. " روضه خوانى". Ver tacziya, en E.I., op. cit., nota 27.

30. Ver nota 9.

31. Ducă'. "Súplica", "invocación", "oración". Ver F.M. PAREJA, op. cit., vol. II, p. 530. 
Kumayl de Qom y Mašhad ${ }^{32}$. A través de la recitación magistral de ciertos episodios y de la modulación de la voz, el narrador es capaz de provocar un estado de ánimo y de sobrecogimiento en su audiencia, que produce un grado de emoción de gran intensidad. El capítulo tercero de la Corónica está enfocado hacia el mismo objetivo que la taziyeh, crear un estado de ánimo intenso en la audiencia, siendo representado, al igual que ésta, en Achura el día diez de Muharram:

"...Y ansí qualquiera que la leyere el día de Axora le dará Allá taala ${ }^{33}$ tanto premio como el que murió xahid ${ }^{34}$..." (f. 64v).

Dato muy importante en este párrafo es el premio que recibe el posible lector u oyente de la obra "... tanto...como el que murió xahid". Hay que aclarar que esta fórmula al final del capítulo tercero, conecta con los planteamientos del teólogo de la escuela de Bagdad az-Zamajšrí y de la chía. Explica az-Zamajšrĩ en su Atwō̄ku d-Dahab ${ }^{35}$ ("Los collares de oro") que, de acuerdo con la tradición, quien llora por Husáin se unirá con él en la eternidad. Este premio alcanzará también al que hace llorar a los demás a causa del dolor que siente por la muerte de Husáin. En este punto la doctrina chií dice que "quien obra para parecerse (tašabbuh) a un grupo está en la categoría de tal grupo"36. Por tanto si se continúa leyendo el manuscrito en este punto, veremos como la intención no es otra que participar, al igual que en una representación de taziyeh, en las características morales elevadas de los personajes que acompañaron a Husáin y murieron mártires:

“...Pues animémonos a leer sus santas bidas y muertes partiçipando de sus méritos ansí letores como trasladadores y oyentes, y quien la mandare trasladar, pidiendo a El Señor de esta máquina criada nos cumpla de su graçia y nos dé buen fin en su conoçimiento, amín" (f. 65v).

A partir de aquí el texto continúa con una relación hagiográfica de los imames; al final de la misma se encuentra el duodécimo Imam, del cual dice entre otras cosas:

“...Su apellido Abul Cáçim El Halifa, El Çálihe. Y es el postrero de los doçe Ymanes de su estirpe y El Ymam El Mehdi, como lo dixo su anteçeçor El Mensajero de Alla çalm. Y el que bendrá a la fin de el tiempo a encontrarse con Çeydina $E_{c ̧ a}{ }^{37}$, alym. $Y$ es a saber que en tiempo de el halifa Muhtamid, que

32. Los jueves por la noche, un recitador profesional recita el Dua Kumayl en la mezquita aljama subido en un púlpito, intercalando episodios de la Batalla de Karbalá y la muerte de Husáin.

33. Allāh ta 'alá, "Allah, Enaltecido".

34. Es decir, tanto como el que murió mártir.

35. Colección de apotegmas y dichos morales compuestos por az-Zamajšrari. Ver E.I., op. cit., nota 13.

36. Cfr. Mayel BAKTASH, op. cit., nota 12 .

37. "Jesús". 
éste tal era tirano y cruel, y temiéndose de sus crueldades y tiranías de éste halifa se retiró y escondió la rama ${ }^{38}$, que por curso de tiempo echaron fruto de tanta bendiçión como será a el mundo. $Y$ esto fue caussa para [ $f^{\circ} 84 r$ ] lo que Alla taala tenía ordenado en su eternidad, que lo encubrió de la bista de la jente....Dichoso y bienabenturado el que alcançare su tiempo y fuere de su compañía. $Y$ dichoso el que entrare en el ymán ${ }^{39}$ por su mano y le siguiere, y fuere de sus soldados y ayudantes a purificar y a limpiar el mundo de su suçiedad y piçina ${ }^{40}$ en él tan araygada, donde tendrán los agrabiadores la paga mereçida y satisfechos los agrabiados, serán acabadas las tiranías y desjechas las potestades de los gobiernos tiranos. Bienabenturados los que le bieren y alcançaren su tiempo" ( $\left.\mathrm{f}^{\circ} 84 \mathrm{v}\right)$.

En este párrafo se encuentran algunos de los postulados principales de la chía referentes al duodécimo Imam, "El Señor de los Tiempos"41, que muestran con total evidencia la adscripción del manuscrito a la escuela chiir $^{42}$.

Con este breve repaso de algunos de los elementos más característicos de la "Cơrónica", se puede confirmar, con bastante seguridad, la hipótesis que enunciábamos al principio de este estudio, es decir, se está ante un texto extraordinario cuyo tema chí es novedoso entre los moriscos. Sin embargo afirmar la existencia de una comunidad chií hispanohablante sería quizás un poco atrevido o al menos no se tienen datos suficientes como para afirmarlo. Sí se puede afirmar, al menos, que se usaba el texto entre los moriscos exilados.

Si se analizan las características del texto se verá que es un compendio de material didáctico para la formación islamológica de los moriscos. Este manuscrito que fue encargado por el morisco Muhámmad Rubio, es de suponer que no sólo sirvió para un uso privado e individual, sino que, como bien se puede leer en el mismo, parece que el encargo de su traducción fue una obra piadosa para beneficio de los moriscos hispanohablantes en general ${ }^{43}$.

Lo verdaderamente clarificador de este manuscrito es el hecho de encontrarnos con un texto que nos dice mucho acerca de la comunidad de exiliados andalusíes del s. XVII, de sus anhelos culturales, de sus necesidades de inculturizarse en lo que era su civilización. En definitiva un intento por parte de los exilados de ponerse al día, una necesidad de reencontrarse con la sociedad islámica de la cual nunca se habían separado.

\footnotetext{
38. "Progenie".

39. "Fe".

40. Lugar de pez y sentina.

41. En árabe: Sáhib az-zamān.

42. Ver nota 26.

43. “...Juntamente el que a trasladado ésta, pide una fetexa de limosna. Y otra pide el dueño del libro por aber pagado su dinero de traduçirlo de arábigo en castellano para que se huelguen los mumines de su naçión de leherlo" (f. 65r).
} 